\title{
The role of oligodendroglial dysfunction in amyotrophic lateral sclerosis
}

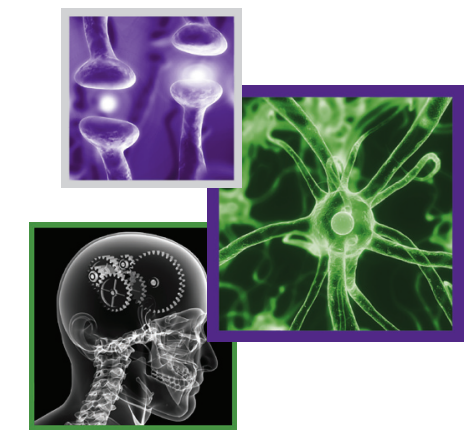

\author{
Annelies Nonneman ${ }^{1,2}$, Wim Robberecht ${ }^{1,2,3}$ \& Ludo Van Den Bosch ${ }^{* 1,2}$
}

\section{Practice points}

- Oligodendrocytes are a cell type of major importance to neurons.

- Gray matter oligodendrocytes in amyotrophic lateral sclerosis (ALS) mice start to degenerate before motor neurons.

- NG2+ oligodendroglial precursor cells try to compensate for oligodendrocyte loss by increasing their proliferation rates and by starting to differentiate into oligodendrocytes. However, the newly generated oligodendrocytes are dysfunctional due to their immature and not fully differentiated state.

- Different types of insults can be responsible for the oligodendrocyte pathology seen in ALS.

- Oligodendrocytes play a key role in the pathogenesis of ALS.

SUMMARY Healthy oligodendrocytes are crucial for neurons and abnormal functioning of these cells is involved in several neurodegenerative diseases. We will focus on oligodendroglial pathology in amyotrophic lateral sclerosis (ALS), an adult-onset progressive neurodegenerative disease characterized by selective motor neuron loss. Recent discoveries shed new light on the crucial role of oligodendrocytes in this fatal disease. We will first give an overview of the importance of good-functioning oligodendrocytes for neuronal health, in particularformotor neurons. Subsequently, we will discuss the recent data on oligodendroglial abnormalities in ALS. We conclude that oligodendrocytes should be considered as important contributors to motor neuron degeneration. As a consequence, oligodendrocytes are a promising new therapeutic target for ALS and other neurodegenerative diseases.

Oligodendrocytes are important in the context of neurodegeneration as they insulate axons with an essential myelin sheath $[1-3]$ and they provide neurons with metabolic support $[4,5]$. Abnormalities in one of these two functions cause a number of neurodegenerative diseases $[1,2,4,5]$. In this review, we will give an overview of the known pathological abnormalities in oligodendrocytes and their involvement in the pathogenesis of amyotrophic lateral sclerosis (ALS).

ALS is a devastating neurodegenerative disease characterized by the loss of both upper and lower motor neurons. This progressive disease starts at adult age by showing symptoms such as muscle weakness, atrophy and spasticity, and subsequently evolves into paralysis. Usually patients die within 3-5 years after the first symptoms were observed [6].

Approximately $10 \%$ of ALS patients suffer from a hereditary form of the disease, which is caused by mutations in different genes [7]. The most prevalent genetic causes are hexanucleotide repeats in C9orf72 [8-10] and mutations in superoxide dismutase 1 (SOD1) [11]. Other less frequent

\section{KEYWORDS}

- amyotrophic lateral sclerosis $\bullet$ monocarboxylate transporter $\bullet$ motor neuron - myelin basic protein - neurodegeneration $•$ NG2 glial cell $\bullet$ oligodendrocyte

'KU Leuven - University of Leuven, Department of Neurosciences, Experimental Neurology and Leuven Research Institute for Neuroscience and Disease (LIND), B-3000 Leuven, Belgium 
ALS-causing mutations occur in TAR DNA binding protein 43 (TDP-43) [12], fused in sarcoma (FUS) [13,14], valosin-containing protein (VCP) [15] and many others [7].

Transgenic mice overexpressing human mutant SOD1 were generated as a model to study ALS. This animal model has been very important to the field, as it recapitulates human ALS pathology with adult-onset, progressive and ultimately fatal motor neuron degeneration [16]. Elaborate studies using mutant SOD1 mice revealed that motor neuron degeneration is a non-cell autonomous process. This means that mutant SOD1 expression in non-neuronal cells has deleterious effects that contribute to neuronal death. Chimeric mice in which motor neurons expressing mutant SOD1 are surrounded by wild-type non-neuronal cells show a significant prolongation of survival [17]. Selective removal of mutant SOD1 from microglia clearly slows down disease progression [18]. Similar effects were observed after selective elimination of mutant SOD1 from astrocytes [19]. These studies all strongly support the non-cell autonomous contribution in the pathogenesis of ALS.

Until recently, the involvement of other glial cell types, such as oligodendrocytes and the oligodendroglial precursor cells, in the pathogenesis of ALS was not profoundly explored. This is remarkable, as abnormalities of the oligodendrocytes, such as alterations in myelin composition and the presence of pathological inclusions, were already reported in several pathological studies of spinal cords from both ALS patients and rodent models [20-23].

In this review, we will highlight the pathological abnormalities in oligodendrocytes and oligodendroglial precursor cells and their involvement in the pathogenesis of ALS. We will start this review by explaining what oligodendrocytes are, how they develop and how important their normal functioning is for neurons. Subsequently, we will discuss the oligodendroglial pathology observed in ALS and we will conclude this review by discussing whether oligodendrocyte pathology is primary or secondary to motor neuron degeneration. From a therapeutic point of view, the latter is an important question to address, since it elucidates the potential of oligodendrocytes as a therapeutic target.

\section{Healthy oligodendrocytes in the centra} nervous system

Oligodendrocytes represent a highly specialized glial cell type in the central nervous system
(CNS) that closely interacts with the axons of neurons. The most typical characteristic of this cell type is the ability to generate a compact multilayered myelin sheath around the axon $[1-3,24,25]$. Myelin is composed of lipids (mainly cholesterol) and proteins. The most abundant protein components of the myelin sheath are proteolipid protein (PLP) and myelin basic protein (MBP). This myelin sheath makes it possible to propagate action potentials very fast and efficient over long distances along the axons through saltatory conduction. Saltatory conduction is made possible due to the interruption of the myelin sheath at regular distances by gaps, the so-called nodes of Ranvier [26]. At these nodes of Ranvier electrical activity can be generated in order to propagate the action potential efficiently from one node of Ranvier to the next one.

Another important function of the oligodendrocytes is their ability to provide neurons with energy support which is essential to maintain their functional integrity $[4,5]$. Monocarboxylates, including lactate, pyruvate and keton bodies, are a class of essential energy substrates for the CNS. These energy substrates are transported across membranes by monocarboxylate transporters (MCTs). The most abundant lactate transporter in the CNS is monocarboxylate transporter-1 (MCT1) and is mainly expressed by oligodendrocytes at high levels, sometimes demonstrated in astrocytes and endothelial cells, and it is absent in NG2 glial cells and microglia [4,27-30]. Downregulation or inhibition of MCT1 results in axon degeneration, emphasizing the importance of lactate for neurons [4,5]. As a consequence, the oligodendrocytes are considered as the principal suppliers of metabolic energy to axons and neurons [4,5]. Lactate is also important for the oligodendrocytes as it supports oligodendrocyte development and it is an essential nutrient for the synthesis of lipids needed for myelination [28].

During development of the CNS, oligodendrocytes are generated from multipotent neural stem cells (NSCs) located in the ventral part of the neural tube [31-34]. These NSCs in the embryonic spinal cord give rise to glial progenitor cells and subsequently oligodendroglial precursor cells. These cells are also called NG2+ glial cells because of their characteristic expression of the proteoglycan NG2 [35-37]. During late embryonic and early postnatal stages, NG2+ glial cells differentiate into oligodendrocytes that further maturate into functionally mature myelinating 
cells. Oligodendrocytes wrap their membrane several times around an axon to form a multilayered myelin sheath. Every oligodendrocyte can myelinate up to 50 different axons [38,39]. Each step in this process of development and maturation is characterized by the expression of specific cell markers (Figure 1A).

Oligodendrocyte generation and myelination are not restricted to development, it also takes place during adult life up to the fifth decade $[40,41]$. With aging, myelin is slowly getting thinner and myelin breakdown occurs, resulting into slower propagation of action potentials [40,41]. This occurs in every healthy adult. However, during neurodegeneration, as in Alzheimer's disease, this process occurs more rapidly [40]. Once oligodendrocytes are terminally differentiated, they are considered post-mitotic [42]. Their main functions at that point are maintenance of the myelin sheath and metabolic support of the neurons, both highly demanding functions in terms of energy requirements. However, a pool of mitotically active NG2 + oligodendroglial precursor cells is maintained during adult life $[37,43]$. These cells are still able to proliferate and can differentiate into oligodendrocytes, but their proliferation and differentiation rate during adulthood is modest compared to developmental stages (Figure 1B) [37,43]. Beside the ability to generate new oligodendrocytes, NG2+ glia form synaptic contacts with axons. Due to these cellular contacts in combination with the variety of receptors and the NG2 proteoglycan present on NG2+ glia, they are specialized to survey the CNS and respond to changes in the integrity of the CNS $[36,44,45]$.

In response to acute CNS injury and demyelination, the NG2 + oligodendroglial precursor cells increase their proliferation and differentiation rate $[37,46-50]$, in order to generate new oligodendrocytes (Figure 1C). However, the newly formed oligodendrocytes are often abnormal and remyelination is incomplete [47].

Although NG2+ glia are also called oligodendrocyte precursor cells, these precursor cells have a broader lineage potential [35,36,51,52]. NG2+ glia do not only differentiate into oligodendrocytes [53-56], but are also able to differentiate into small subsets of neurons [53,57], astrocytes [54,55,58], microglia [59], Schwann cells [56] and pericytes [59]. However, NG2+ glial cells do not always generate all these cell types. Their differentiation capacity is highly dependent on the developmental stage $[52,60]$, the local environment and the type of CNS injury [56,58,59].
In conclusion, oligodendrocytes and their NG2+ precursor cells are very important for normal functioning, health and survival of neurons in the CNS. Alterations in the physiological functions of the oligodendrocytes result in dramatic effects for the neurons that can lead to neurodegeneration $[1,2,4,5]$.

\section{Oligodendrocyte pathology in ALS patients}

The involvement of non-neuronal glial cells, such as microglia and astrocytes, is a wellstudied aspect of ALS pathology. However the oligodendrocytes and their progenitor cells are glial cell types that have been largely ignored for years in the context of ALS. This is surprising as abnormalities of the oligodendrocytes, such as pathological inclusions, were observed in affected postmortem tissue of ALS patients. For example, pathological aggregates sequestering the ALS-linked protein TDP-43 occur in the cytoplasm of oligodendrocytes from both sporadic and familial ALS patients [10,21,61-65]. Also, another ALS-linked protein, namely FUS, was found to be sequestered into inclusions in the cytoplasm of oligodendrocytes from ALS patients with mutations in the FUS gene [22]. The abundance of FUS inclusions in oligodendrocytes seems to correlate with age of onset. Early-onset patients have predominantly neuronal cytoplasmic FUS inclusions and very few oligodendroglial FUS inclusions. On the other hand, patients with late-onset disease are characterized by highly abundant FUS inclusions in the cytoplasm of oligodendrocytes, widespread throughout the CNS [22].

Recently, oligodendrocytes were studied in more detail. In addition to the presence of inclusions, myelin abnormalities, demyelination and even oligodendrocyte degeneration are present in the gray matter of the ventral spinal cord of ALS patients [66]. This is the case in both sporadic and familial cases. Not only oligodendrocytes are affected in ALS patients, but also NG2+ oligodendroglial precursor cells show reactive changes [66]. A clear augmentation of the NG2 immunoreactivity and thick hypertrophic NG2+ processes were reported in ALS patients, both of which are absent in control subjects [66]. These abnormalities observed in the oligodendroglial lineage cells of ALS patients are a strong indication that these cells could be implicated in ALS pathogenesis. 


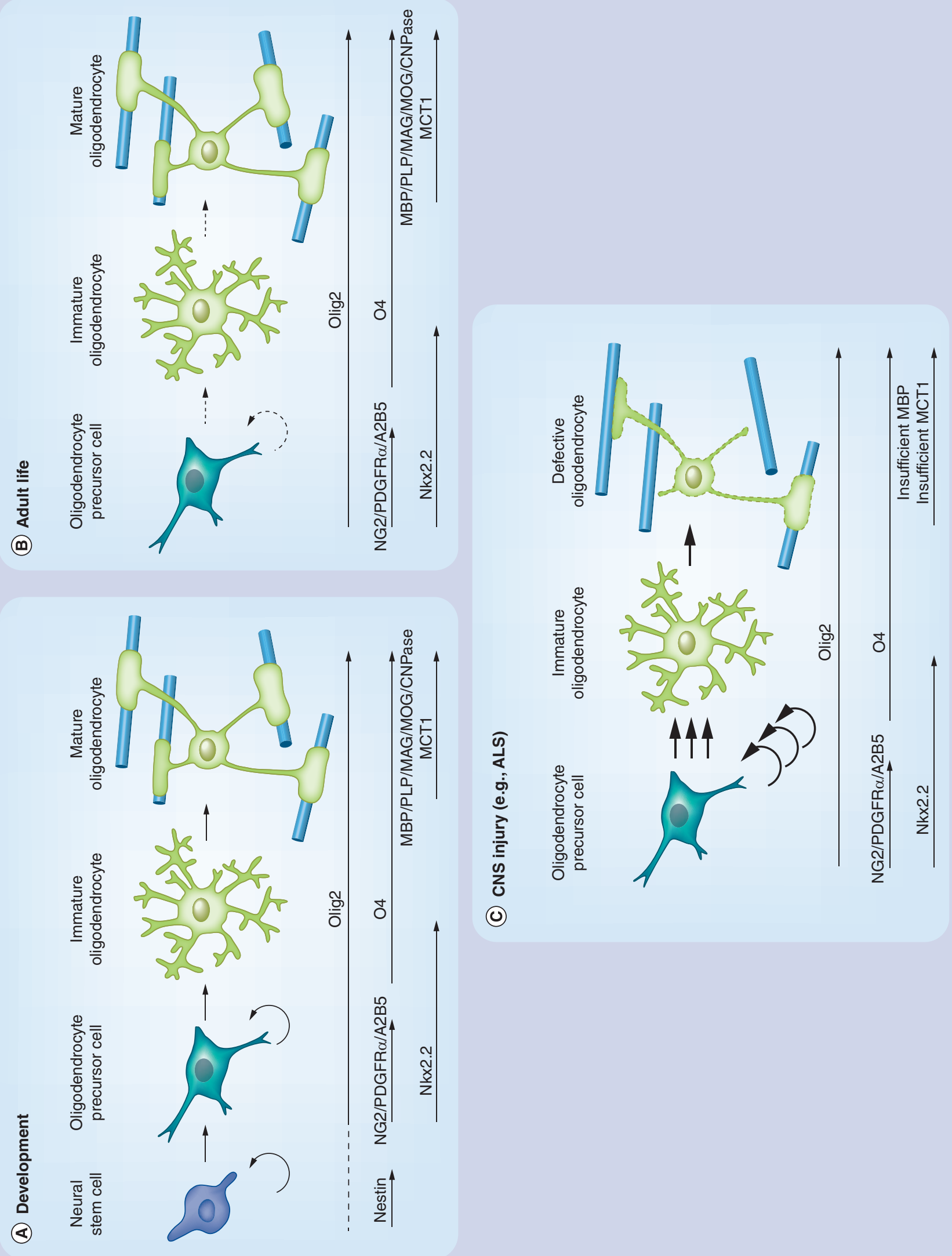


Figure 1 (see facing page). Oligodendrocytes during development, adult life and in response to central nervous system injury. (A) During embryonic development of the CNS, oligodendrogenesis starts from multipotent neural stem cells. Neural stem cells, characterized by the expression of nestin, proliferate and give rise to oligodendrocyte progenitor cells - also called NG2+ glial cells - due to the characteristic expression of the proteoglycan NG2 and additionally PDGFR $\alpha$, tetrasialoganglioside A2B5 and the transcription factor Nkx2.2. During late embryonic and early postnatal stages, NG2+ glial cells differentiate into immature oligodendrocytes that further maturate into functionally mature myelinating cells. Oligodendrocytes are recognized by the expression of the marker O4-antigen. MBP, PLP, MAG, MOG, CNPase and MCT1 are markers expressed by mature myelinating oligodendrocytes and are absent in their precursor cells. Characteristic for the entire oligodendrocyte lineage is the expression of the oligodendrocyte transcription factor Olig2. (B) During adult life, oligodendrocytes are in a stable myelinating state. A pool of mitotically active NG2+ oligodendrocyte precursor cells is maintained, but the proliferation and differentiation rate is rather limited. (C) In response to CNS injury and demyelination, the NG2+ oligodendrocyte precursor cells increase their proliferation rate extensively and differentiation into oligodendrocytes is enhanced. However, the newly formed oligodendrocytes can function abnormally and/or can show impairment of their myelin repair efficiency. For example in amyotrophic lateral sclerosis, the reduced ability of the new oligodendrocytes to myelinate axons and to give trophic support to neurons is indicated by a reduction in the expression of the markers MBP and MCT1. CNPase: 2-3-cyclic nucleotide 3-phosphodiesterase; MAG: Myelin-associated glycoprotein; MBP: Myelin basic protein; MCT1: Monocarboxylate transporter-1; MOG: Myelin-oligodendrocyte glycoprotein; PDGFR $\alpha$ : PDGF receptor $\alpha$; PLP: Proteolipid protein.

\section{Oligodendrocyte degeneration in ALS mouse models}

Postmortem tissue from ALS patients only revealed the presence of inclusions, oligodendrocyte degeneration and reactive changes of the NG2+ oligodendroglial precursor cells. The exact importance and involvement of oligodendrocytes in the pathogenesis of ALS have only been elucidated recently through extensive study of the ALS mouse models $[4,65,66]$.

First, in line with the findings in ALS patients, oligodendroglial inclusions were also observed in the spinal cord of ALS mice [67]. Second, we and others recently discovered that gray matter oligodendrocytes in the spinal cord of mutant SOD1 mice start to degenerate before the first symptoms of motor neuron degeneration become apparent $[65,66]$. An important indication for this oligodendrocytic degeneration is the abnormal morphology of these cells. As a function of disease progression, an increasing number of spinal cord oligodendrocytes show a thickened, irregularly shaped cell body, enlarged cytoplasm and elongated reactive processes [65]. Oligodendrocytes acquiring these morphological changes are defined as dysmorphic and are in an apoptotic state, as these dysmorphic oligodendrocytes show cleaved caspase- 3 immunoreactivity $[65,66]$. Moreover, these irregularly shaped oligodendrocytes undergo nuclear alterations such as chromatin condensation [66], which is a hallmark of apoptotic cell death [68]. The number of dysmorphic oligodendrocytes in $\mathrm{SOD}^{\mathrm{G} 93 \mathrm{~A}}$ mice is significantly increased (more than twofold) before disease onset (asymptomatic day 60), and is progressively increasing (more than fivefold) with disease progression [65]. Oligodendrocyte degeneration is most prominent in the ventral gray matter and is to a lesser extent also present in the ventral white matter $[65,66]$. Besides the morphological changes and the immunoreactivity for cleaved caspase-3, further evidence for oligodendrocytic cell death is the dense clustering of reactive microglia around the degenerating oligodendrocytes [66]. As microglia are known to be attracted by apoptotic cells [69], this indicates that oligodendrocytes are dying.

Additional evidence for oligodendrocytic degeneration came from genetic fate tracing of the oligodendrocytes using Plp-CreER:ROSA26EYFP:SOD $1^{G 93 A}$ mice. By using a tamoxifeninducible oligodendrocyte-specific Cre-line (Plp-CreER), the oligodendrocytes present at the moment of tamoxifen administration (asymptomatic stage) are labeled with yellow fluorescent protein (YFP) via Cre-Lox mediated recombination and can be followed over time $[65,66]$. This approach confirms a decrease in the number of YFP-labeled oligodendrocytes in the spinal cord of SOD1 $1^{\mathrm{G} 93 \mathrm{~A}}$ mice before signs of motor neuron degeneration appear $[65,66]$. As a function of disease progression in the SOD $1^{\mathrm{G} 93 \mathrm{~A}}$ mice, this number of YFP-labeled oligodendrocytes progressively decreases and is a measure of oligodendrocyte degeneration in ALS $[65,66]$.

\section{Oligodendrocyte precursor cells try to compensate for oligodendrocyte loss}

Although oligodendrocytes degenerate progressively, the overall number of oligodendrocytes does not change throughout the course of disease and is not different from the density of oligodendrocytes in control SOD $1^{\mathrm{WT}}$ mice $[65,66]$. This suggests that degenerating oligodendrocytes 
are actively replaced by a compensatory mechanism. As oligodendrocytes are post-mitotic cells [42], the NG2 + oligodendrocyte precursor cells are responsible for this replacement. Reactive changes of the $\mathrm{NG} 2+$ glial cells in SOD1 ${ }^{\mathrm{G} 93 \mathrm{~A}}$ mice are reported. For instance, a significant increase in NG2 + immunostaining was observed at symptomatic disease stages in the spinal cord of SOD $1^{\mathrm{G} 93 \mathrm{~A}}$ mice, while rarely observable in SOD1 ${ }^{\text {WT }}$ mice [70]. Not only the upregulation of the expression of the proteoglycan NG2 is responsible for this increased $\mathrm{NG} 2+\mathrm{immu}$ nostaining, but mainly the abnormally enhanced proliferation of the $\mathrm{NG} 2+$ glia is a strong contributor. The NG2+ glia are considered the most proliferating cell type in spinal cord of ALS mice [43,70]. The highly reactive, dividing NG2+ glial cells are mainly localized in the lumbar spinal cord ventral gray matter and this already before mice show symptoms of disease $[43,70]$.

In addition to the increased rate of proliferation, fate mapping experiments in which the $\mathrm{NG} 2+$ glia were labeled showed enhanced differentiation of the NG2+ glia [43]. As mentioned before, NG2 + glia are multipotent cells that can differentiate into several cell types $[36,51,52]$. Differentiation capacity depends on the developmental stage $[52,60]$, the local environment and the type of CNS injury [56,58,59]. However, in vivo experiments using SOD1 ${ }^{\mathrm{G} 93 \mathrm{~A}}$ mice revealed that the NG2+ glial cells in ALS are not multipotent, but restricted to the oligodendrocytic lineage $[43,65,66]$. The NG2+ glial fate mapping experiments showed exclusive differentiation into oligodendrocytes, while no in vivo evidence for differentiation into neurons, astrocytes and microglia was found in ALS [43]. The latter is in contrast with an in vitro study reporting on the capability of a SOD1 ${ }^{\mathrm{G} 93 \mathrm{~A}} \mathrm{NG} 2+$ glial cell line to differentiate into astrocytes [70], confirming the importance of the local environmental conditions for the differentiation ability of $\mathrm{NG} 2+$ glia. The enhanced differentiation of $\mathrm{NG} 2+$ cells into oligodendrocytes in SOD $1^{\mathrm{G} 93 \mathrm{~A}}$ mice was also confirmed indirectly by genetic labeling of the oligodendrocytes (Plp-CreER:ROSA26YFP:SOD $1^{G 93 A}$ mice), as described in the previous section [65]. The number of YFP-labeled oligodendrocytes in spinal cord from SOD1 ${ }^{\mathrm{G} 93 \mathrm{~A}}$ mice significantly decreases with disease progression. In contrast, the proportion of unlabeled oligodendrocytes, as a measure of newly generated oligodendrocytes, is significantly increased in spinal cord from symptomatic $\mathrm{SOD}^{\mathrm{G} 93 \mathrm{~A}}$ mice [65]. As a consequence, the total number of oligodendrocytes, both labeled and unlabeled, remains the same [65].

In conclusion, the degeneration of oligodendrocytes is compensated by increased proliferation and differentiation of NG2 + glial cells into oligodendrocytes. In this way the density of oligodendrocytes remains constant throughout the disease course.

\section{Newly generated oligodendrocytes are dysfunctional in ALS}

As discussed before, a rescue mechanism of proliferation and differentiation of NG2 + glia into oligodendrocytes can be activated in response to extensive oligodendrocyte degeneration. However, no accumulation of oligodendrocytes occurs, but an equilibrium between the rate of oligodendrocyte loss and the rate of oligodendrocyte generation is achieved in ALS mice $[65,66]$.

Remarkably, the newly generated oligodendrocytes in the SOD1 ${ }^{\mathrm{G} 93 \mathrm{~A}}$ spinal cord are often associated with degenerating axons [66]. This finding suggests that these axons already went through at least one cycle of de- and remyelination. In addition, this may indicate that the new oligodendrocytes are not able to maintain their axons healthy, thereby raising the question of whether these new cells are functionally normal in ALS mice or dysfunctional and less effective due to, for example, the presence of ALScausing mutations. The latter hypothesis is based on multiple sclerosis lesions and experimental models of demyelination, where NG2 glial cells are suggested to be able to generate myelinating oligodendrocytes responsible for remyelination and consequently can rescue the axon [71].

Morphological examination of these newly generated oligodendrocytes showed irregularly shaped somata and highly branched processes, defined as dysmorphic morphology [65]. Electron microscopic examination of the axon myelin sheath in the spinal cord of SOD ${ }^{\mathrm{G} 93 \mathrm{~A}}$ mice [66] and $\mathrm{SOD}^{\mathrm{G} 93 \mathrm{~A}}$ rats $[20]$ revealed myelin abnormalities in the gray matter, such as the presence of swollen electron dense myelin sheaths, myelin debris, partially myelinated axons, immature myelin sheaths and non-myelinating oligodendrocytes.

The adult-born oligodendrocytes also show several functional defects $[4,20,65,66]$. First of all, the lipid and protein composition of the myelin sheath is altered. The total lipid content (mainly cholesterol) in whole spinal cord is 
reduced before disease onset and decreases progressively with disease course [20]. Disruption of cholesterol metabolism may contribute to motor neuron degeneration in ALS, as inactivation of liver $\mathrm{X}$ receptor beta results in disruption of cholesterol metabolism and can lead to adultonset motor neuron degeneration in mice [72]. The levels of myelin-forming proteins have also been reported to progressively decrease during disease $[20,65,66]$. Most prominent is the decrease in the levels of MBP. MBP is the second most abundant protein component of myelin and is responsible for the formation, compaction and stabilization of myelin [73]. These myelin defects are also detected in the spinal cord and motor cortex of ALS patients, but are absent in control subjects [66]. A thick, well-developed, well-organized and compact myelin sheath has neuroprotective properties [74], and is very important for fast and efficient propagation of action potentials along the axons. Obviously, the myelin abnormalities in ALS are detrimental for the health of motor neurons and could be considered as a contributing factor to neurodegeneration. However, the absence of myelin alone is not sufficient for axonal degeneration, unless it occurs in combination with oligodendroglial injury or inflammation [2].

Besides myelin defects, oligodendrocytes also fail to supply axons with metabolic energy substrates $[4,65]$. MCT1 is a good marker for metabolic support by the oligodendrocytes, as it is the major transporter of energy substrates (including lactate, pyruvate and ketone bodies) to the CNS neurons and it is expressed abundantly on oligodendrocytes $[4,5]$. MCT1 expression levels are predominantly decreased in the ventral horn of the spinal cord gray matter of symptomatic SOD $1^{\mathrm{G} 93 \mathrm{~A}}$ mice $[4,65]$. The MCT1 decrease was confirmed in the motor cortex of ALS patients, while unaffected brain regions show normal MCT1 levels [4]. Due to the reduction of MCT1 in ALS, the lactate transport from oligodendrocytes to neurons is diminished. This causes disturbances of the local energy supply and can lead to axonal dysfunction, axonal damage and even neuronal loss in cell culture models, as well as in mouse models $[2,4,5]$. Besides exporting lactate, MCT1 is also able to import lactate into the oligodendrocytes. This is due to the fact that the direction of transport depends on the concentration of lactate and hydrogen ions in the intracellular and extracellular compartment [27]. As a consequence, reduced MCT1 levels in ALS can also have detrimental effects on the oligodendrocytes. Oligodendrocytes need lactate for energy production in order to maintain proper cell functioning, and for lipid synthesis to make myelin [28,75]. Energy deprivation experiments in vitro cause oligodendroglial loss and reduced myelination due to a lower lactate import via MCT1 [28]. When exogenous lactate is supplied, myelination is rescued. The hypothesis could be that decreased MCT1 levels do not only induce neuronal damage, but can also result in oligodendroglial damage and impaired myelination. However, inhibition or downregulation of MCT1 did not result in a loss of oligodendrocytes or myelin defects. Only motor neuron degeneration was observed, which could be prevented by exogenous lactate administration [4]. Although speculative, these experiments indicate that mainly lactate export, and not import, is affected when MCT1 levels are decreased in ALS.

The reduction in lipid content, MBP levels and MCT1 levels in the spinal cord of SOD1 $1^{\mathrm{G} 93 \mathrm{~A}}$ mice cannot be explained by loss of oligodendrocytes as the density of the oligodendrocytes does not change during disease progression due to the generation of newly differentiated oligodendrocytes $[65,66]$. However, it indicates that the newly generated oligodendrocytes are unable to function properly, probably due to their immature developmental state, which could contribute to neurodegeneration.

\section{The critical involvement of oligodendrocytes in ALS pathology: effect on disease onset \& survival}

Based on the data discussed in the previous sections, two important questions arise: 1) to what extend does oligodendrocyte pathology contribute to the pathogenesis of ALS, and 2) is the presence of ALS-causing mutant genes, such as mutant SOD1, in the oligodendroglial lineage responsible for oligodendrocyte degeneration on one hand and for the immature dysfunctional state of the newly generated oligodendrocytes on the other hand?

To address these questions, mutant SOD1 was selectively removed from the NG2+ oligodendroglial precursor cells in mutant $\mathrm{SOD} 1^{\mathrm{G} 37 \mathrm{R}}$ mice [66]. Consequently, all oligodendrocytes newly generated from these NG2+ glia also lacked mutant SOD1. This experiment showed a clear delay in disease onset and a significant prolongation of survival in ALS mice. However, the total 
disease duration (time between symptom onset and death) was not altered, indicating that the longer survival is completely explained by a delay in disease onset. In addition, these mice exhibit less activation of microglia and astrocytes, and normal levels of MCT1 are maintained.

This experiment suggests a key role for oligodendroglial cells in the pathogenesis of ALS. The presence of mutant SOD1 in all cells of the oligodendroglial lineage, both NG2 + glial cells and oligodendrocytes, has devastating effects on the health and function of the oligodendrocytes. Consequently, oligodendrocytes fail to properly support their adjacent neurons, which may be one of the critical events in the initiation of motor neuron degeneration in ALS.

\section{What causes oligodendrocyte pathology} in ALS?

\section{- ALS-causing mutant genes}

A logical first consideration, based on the knowledge from the previous section, is that the expression of ALS-causing mutant genes in oligodendrocytes is an important cause of oligodendrocyte pathology. Oligodendrocytes are extremely vulnerable to the deleterious effects of the expression of genes related to neurodegenerative diseases $[66,76,77]$. For example, when a human mutant form of tau associated with 'frontotemporal dementia with parkinsonism linked to chromosome 17' is expressed selectively in oligodendrocytes [76], it impairs oligodendroglial function and disrupts the myelin sheath. Subsequently, this leads to defective axonal transport, motor deficits, axonal degeneration and even neuronal loss. In addition, mutations in ALS-associated genes, such as SOD1, FUS and TDP-43, are harmful to oligodendrocytes, because they lead to the formation of protein aggregates, causing endoplasmic reticulum stress and consequently apoptosis [66]. The experiment in which mutant SOD1 is eliminated from the $\mathrm{NG} 2+$ glial cells and consequently also from the newly generated oligodendrocytes, described in the previous section [66], confirms this hypothesis. It clearly shows that the presence of mutant SOD1 in cells of the oligodendroglial lineage has devastating effects on the health and survival of oligodendrocytes, and hence selective elimination of mutant SOD1 from oligodendroglial cells can affect disease onset.

Despite the ubiquitous expression of mutant SOD1 or other ALS-causing genes (in all cell types, in affected and unaffected areas), oligodendroglial degeneration mainly occurs in the spinal cord ventral horn and motor cortex, while oligodendrocyte pathology is limited or absent in other unaffected regions. In addition, oligodendrocyte pathology also takes place in sporadic ALS patients [62,65] independent of the presence of a known ALS-causing mutation. Hence, other causes have to be taken into account. The presence of ALS-causing mutant genes probably renders the oligodendrocytes more vulnerable to these other stress factors. Additional triggers for oligodendrocyte pathology can be toxic factors released by adjacent glial cells (microglia and astrocytes), oxidative damage, excitotoxicity or alterations in gene expression.

\section{- Reactive glial cells}

Substantial evidence is available showing that activated microglia and astrocytes are cytotoxic to oligodendrocytes and their precursor cells. Both in vitro [78-82] and in vivo [83,84] studies show that microglia produce reactive oxygen species (ROS) and secrete proinflammatory cytokines that are cytotoxic to oligodendrocytes. Exposure of oligodendrocytes to ROS produced by microglia induces single-stranded breaks in the oligodendroglial DNA [79]. Besides being a damaging insult to DNA, ROS are also responsible for alterations in the membranes and organelles of the oligodendrocytes [79]. Mitochondrial disruption has been reported and results in an energy deficit for the oligodendrocytes and subsequently cell death through apoptosis [85].

In addition, oligodendrocyte precursor cells are also highly vulnerable to the harmful effects of activated microglia $[82,85]$. Oligodendrocyte precursor cell death can be induced by ROS (resulting in acute degeneration) and proinflammatory cytokines, such as TNF- $\alpha$ (resulting in delayed degeneration). Activated microglia are also able to block oligodendroglial precursor cell differentiation $[82,84]$. These events result in immature oligodendrocytes with shorter and fewer processes failing to produce MBP [82] and resemble the dysfunctional immature newly differentiated oligodendrocytes observed in ALS. Transplantation experiments in rats with myelination defects [84] showed that normal myelination is achieved when oligodendrocyte precursor cells are transplanted before microglial activation. However, it resulted in death of the oligodendrocyte precursor cells and defective 
myelination when these cells were transplanted at the peak of microglial activation [84]. This could be prevented by microglial inactivation pretreatment [84]. The unsuccessful and incomplete differentiation of oligodendrocyte precursors could be due to the damage induced by cytokines released by activated microglia. Alternatively, incomplete differentiation can result from reduced secretion of growth factors or trophic factors involved in oligodendrocyte differentiation and maturation. These factors include insulin-like growth factor-1 (IGF-1) and ciliary neurotrophic factor (CNTF), which are normally released by resting microglia [82,86-88].

Astrocytes are also known to communicate with oligodendrocytes either directly through several connexins, or indirectly through secreted molecules that regulate oligodendrocyte precursor cell proliferation, differentiation and oligodendrocyte survival [89]. Several studies report a toxic gain of function of reactive astrocytes in ALS [90-92]. Reactive astrocytes secrete soluble factors, such as inflammatory cytokines, that are toxic for motor neurons [90,91]. In addition, reactive astrocytes also show an upregulation of the expression of nitric oxide synthase (NOS) [92], which reflects an increased production of damaging reactive oxygen and nitrogen species, making them toxic for motor neurons. Possibly, this reactive astroglial toxicity may also target the oligodendrocytes.

\section{- Oxidative damage}

Oxidative damage to oligodendrocytes and the oligodendrocyte maturation process can also be independent of activated glia [93,94]. In ALS patients and mouse models, oxidative damage to mRNA is present in oligodendrocytes during the asymptomatic stage, when microgliosis has not yet been initiated [94]. Some mRNA species in oligodendrocytes and motor neurons are exceptionally vulnerable to oxidative damage [94]. Among them are mRNA species encoding proteins involved in mitochondrial electron transport and myelination. One of these vulnerable mRNAs oxidized in ALS is MBP [94]. These oxidative changes result in a reduced protein level and can explain the low expression level of MBP and the myelin defects in ALS. Damage to mRNA species involved in mitochondrial electron transport results in defective energy production and increased production of ROS. This increased ROS production enhances oxidative damage [95]. In this way oxidative damage may be one of the main triggers for the initiation of oligodendrocyte dysfunction and myelin defects, and subsequently oligodendrocyte degeneration.

\section{- Glutamate-mediated excitotoxicity}

An additional cause of oligodendrocyte pathology is glutamate-mediated excitotoxicity. Excitotoxicity is not only a process involved in neurodegeneration $[96,97]$, but also affects oligodendrocytes $[2,98,99]$. The thin processes of oligodendrocytes express $\mathrm{Ca}^{2+}$-permeable NMDA receptors [100]. When axons degenerate, large local concentrations of glutamate are released. This activates the oligodendroglial NMDA receptors and subsequently induces an abundant $\mathrm{Ca}^{2+}$ influx and $\mathrm{Ca}^{2+}$ accumulation in myelin [101]. This increase in intracellular $\mathrm{Ca}^{2+}$ is toxic and damages the oligodendrocytes. Ultimately, these oligodendrocytes degenerate. In this way, glutamate-mediated excitotoxicity can contribute to a vicious cycle of neurodegeneration and oligodendrocyte degeneration.

\section{- Alterations in gene expression}

All the aforementioned stress factors can also alter gene expression in the oligodendrocytes, thereby increasing their vulnerability and impairing their maturation and differentiation capacity [93]. Oxidative stress is able to deregulate the expression of key genes involved in differentiation of the oligodendrocyte precursor cells into fully mature myelinating and functional oligodendrocytes [93]. This can explain the differentiation arrest of oligodendrocyte precursor cells and the presence of immature oligodendrocytes in ALS. Although never investigated in the context of ALS, several genes and pathways are known to be involved in differentiation, myelination and regeneration of the oligodendrocytes, which are linked to other diseases $[102,103]$. In this review we will only highlight the most important genes known to be involved in oligodendrocyte differentiation and pathology, such as Notch signaling, Wnt-signaling, Nogo-A, Id2/ Id4 and HERVs. However, many other genes are known to regulate the differentiation of oligodendrocyte precursor cells into fully mature functional and myelinating oligodendrocytes. Additional information can be found in [102].

One of the most important pathways involved in differentiation, myelination and regeneration of the oligodendrocytes is the Notch signaling pathway [104]. Notch has been linked to failure of remyelination occurring in multiple sclerosis 
(MS), despite the fact that high numbers of oligodendrocyte precursor cells and immature oligodendrocytes accumulate in the MS lesions $[105,106]$. It has been shown that components of the Notch signaling pathway are expressed in the MS lesions, such as Notch-1 on NG2+ oligodendrocyte precursor cells, and that expression was decreased in those lesions that succeeded to remyelinate. As a consequence and according to findings in MS, Notch signaling can be involved in the blockage of the differentiation of the oligodendrocyte precursor cells in ALS and can eventually explain the immature state of the oligodendrocytes.

Wnt/ $\beta$-catenin signaling is also an important pathway involved in inhibition of oligodendrocyte differentiation [107-109]. Comparable to the Notch findings in MS lesions discussed above, elevated levels of mRNA transcripts and proteins involved in the Wnt signaling pathway are found in MS lesions [110], linking activation of Wnt signaling to oligodendrocyte pathology. In vitro and in vivo experiments in which Wnt was activated in oligodendrocyte precursor cells resulted in delayed maturation of oligodendrocytes and failure of remyelination $[108,110]$.

Another possible target that can be responsible for the oligodendroglial differentiation arrest in ALS is Nogo-A [111,112]. Increased levels of Nogo-A are found in active demyelinating MS lesions [113] and this correlates with the progression of demyelination [114]. Genetic deletion of Nogo-A or antibodies against Nogo-A reduce demyelination in experimental autoimmune encephalomyelitis [115,116]. Currently, clinical trials with intravenous administration of antibodies against Nogo-A are ongoing in MS patients (GSK122324). If this therapy is effective in MS it could be worthwhile to test it in ALS patients.

The following negative regulators of oligodendrocyte functioning that we will discuss are inhibitor of DNA binding-2 and -4 (Id2 and Id4) [117,118]. These proteins inhibit oligodendrocyte differentiation by maintaining the oligodendrocytes in their proliferative state. In addition, Id 4 is able to coordinate the expression of myelin genes. For example, Id 4 decreases the activity of the MBP promotor, while it does not affect the PLP expression [102,119]. In the context of ALS this Id4 can be a promising target to increase the expression of MBP and to restore the myelinating function of the oligodendrocytes.

Also of interest in the context of altered gene expression are human endogenous retroviruses
(HERVs), which constitute $8 \%$ of the human genome. Normally HERVs are silenced through epigenetic control; however, several studies report activation of HERVs expression in demyelinated MS lesions [120-122] and also in ALS [123]. HERVs can induce demyelination and oligodendrocyte death [122]. In addition, HERVs are able to interfere with the differentiation capacity of oligodendrocyte precursor cells and can have a negative impact on myelin repair [121].

\section{- Three-phase model of damage to oligodendrocytes}

Based on the knowledge concerning the possible causes of oligodendrocyte pathology and dysfunction, we hypothesize that three phases of damaging insults are responsible for the oligodendroglial cell pathology seen in ALS (Figure 2). A first phase of damaging insults includes the presence of ALS-causing genes in the oligodendrocytes. As already mentioned, this is insufficient to induce oligodendrocyte pathology, but probably renders the oligodendrocytes more vulnerable to other stress factors. We hypothesize that another trigger, or maybe more triggers, are needed to induce oligodendrocyte dysfunction and oligodendrocyte degeneration. Oxidative damage can be such an extra trigger. Subsequently, this initial phase of oligodendrocyte damage can be amplified and intensified by the activated microglia and astrocytes, considered as phase two. Meanwhile and in response to the oligodendrocyte damage and degeneration, the NG2 + oligodendroglial precursor cells become reactive and start to proliferate at high rates as they try to compensate for the oligodendrocyte loss. The third phase of damage to the oligodendrocytes at symptomatic disease stages may be due to the damaging environment created by the degenerating motor neurons in combination with the deleterious effects of the very reactive microglia and astrocytes. This maintains a vicious cycle of oligodendrocyte-motor neuron degeneration and can contribute to disease progression. In addition, this damaging environment also affects the differentiation capacity of $\mathrm{NG} 2$ + oligodendroglial precursor cells into new oligodendrocytes, resulting in the presence of immature and dysfunctional oligodendrocytes. Consequently, these immature oligodendrocytes are not able to sustain the neurons properly and aggravate the vicious cycle of oligodendrocytemotor neuron degeneration. 


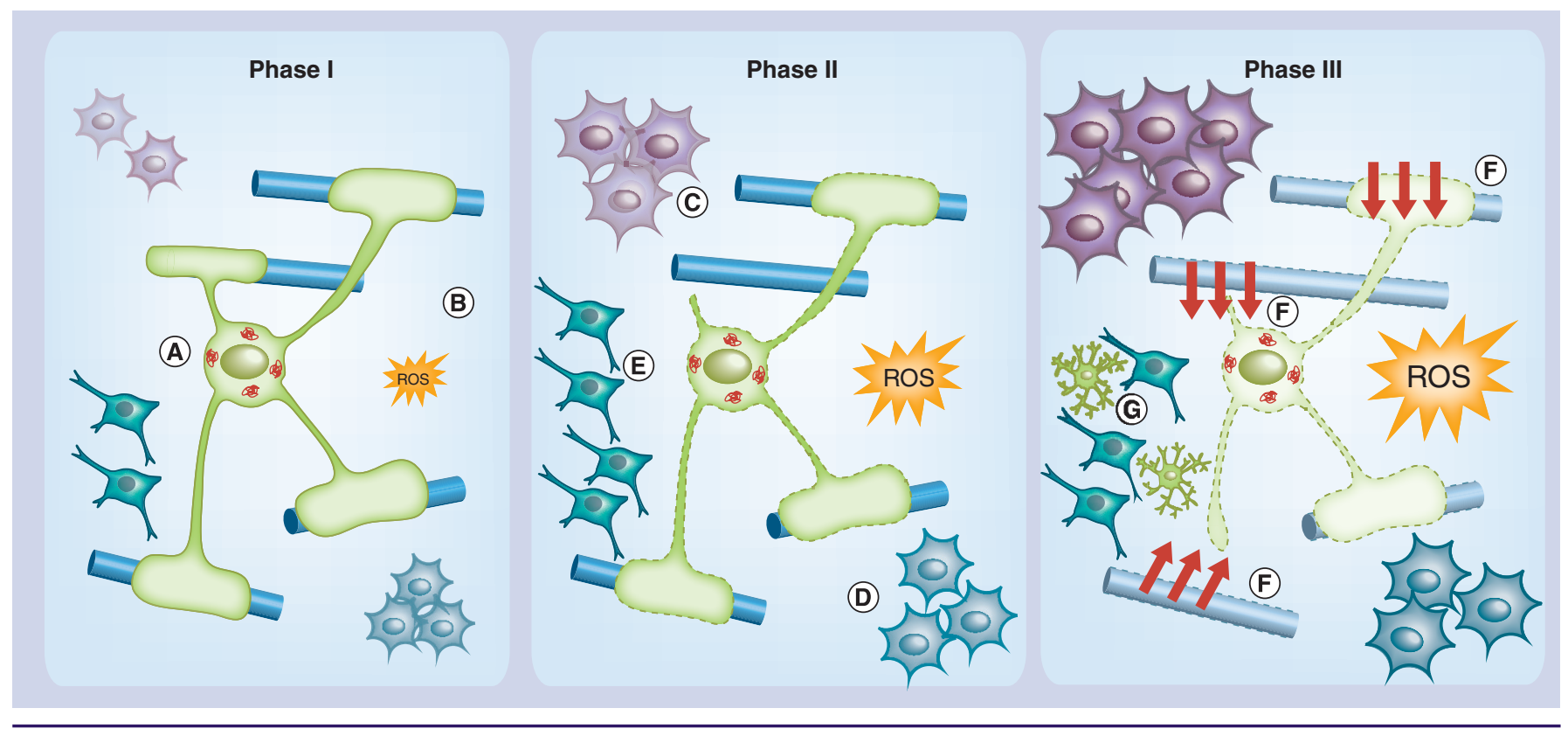

Figure 2. Three phases of damaging insults are responsible for the oligodendroglial cell pathology in amyotrophic lateral sclerosis. The first phase of damaging insults to the oligodendrocytes includes the presence of ALS-causing genes in the oligodendrocytes ([A] red structures). Although this is insufficient to induce oligodendrocyte degeneration, it is probably responsible for rendering oligodendrocytes more vulnerable to additional stress and damaging insults, such as oxidative damage by (B) ROS. This initial phase of oligodendrocyte damage is then amplified and intensified by (C) microglia and (D) astrocytes that become reactive and release proinflammatory cytokines and produce high levels of ROS, considered as phase two. (E) Meanwhile and in response to oligodendrocyte damage and degeneration, the NG2+ oligodendroglial precursor cells become reactive and start to proliferate at high rates, as they try to compensate for the oligodendrocyte loss. The third phase of damage to the oligodendrocytes at symptomatic disease stages can be assigned to the degenerating motor neurons (F). Motor neuron degeneration can result into a toxic environment for oligodendrocytes and can induce excitotoxicity in the oligodendrocytes. These damaging insults, in combination with the deleterious effects of the very reactive microglia and astrocytes and the increasing amount of ROS produced, contribute to disease progression by sustaining a vicious cycle of oligodendrocyte-motor neuron degeneration. In addition, this damaging environment also impairs the differentiation of NG2+ oligodendroglial precursor cells into new oligodendrocytes. This results in the presence of immature and dysfunctional oligodendrocytes (G) that are unable to sustain neurons properly and aggravate the vicious cycle of oligodendrocyte-motor neuron degeneration.

ROS: Reactive oxygen species.

\section{Is oligodendrocyte degeneration \& dysfunction responsible for motor neuron degeneration in ALS?}

From a therapeutic point of view, it is important to determine whether oligodendrocyte pathology occurs prior to motor neuron degeneration and can be considered as a trigger, or whether oligodendrocyte pathology is secondary to motor neuron pathology. In this section we will highlight a number of important findings that provide more insights to give a reasonable, but hypothetical, answer on the 'cause or consequence' question. The observation that extensive degeneration of oligodendrocytes already starts in SOD $1^{\text {G93A }}$ mice long before the motor neurons degenerate $[65,66]$ strongly indicates that motor neuron degeneration is not the cause of oligodendroglial degeneration. However, we do not exclude that when motor neurons start to degenerate this can contribute to the progression of oligodendrocyte pathology by excessive release of glutamate, thereby inducing excitotoxicity [101], or by enhancement of the microglial reactivity and reactive oxygen species production [124].

The second argument for considering oligodendrocyte pathology as a primary event is that deletion of mutant SOD1 from oligodendrocyte progenitor cells and oligodendrocytes significantly delays disease onset [66]. This indicates that prevention of oligodendrocyte dysfunction has a positive effect on the normal function of motor neurons.

Moreover, several studies have confirmed that oligodendrocyte pathology can initiate secondary 
neurodegeneration. This is the case in inflammatory myelin diseases, such as MS and leukodystophies. In MS, progressive secondary axonal loss has been reported in demyelinated MS lesions [125,126]. In Pelizaeus-Merzbacher disease and other leukodystophies, axonal degeneration is a consequence of defective oligodendrocyte differentiation and myelination $[2,127,128]$. Information obtained from animal models of oligodendrocyte injury confirms this. For instance, mouse models in which mature adult oligodendrocytes are genetically ablated in the intact CNS show oligodendrocyte loss followed by microglial activation and subsequently tremor, progressive motor deficits and severe axonal damage [129-132]. In some of these models, the recruitment of NG2+ oligodendrocyte precursor cells was reported $[129,130]$, but remyelination was insufficient to obtain functional recovery, while in other models $\mathrm{NG} 2+$ glial cell proliferation and differentiation were not triggered [131]. However, demyelination alone is not responsible for the induction of axonal degeneration [133]. It must be combined with oligodendroglial dysfunction in order to do so $[2,131]$. Downregulation of the lactate transporter MCT1 illustrates this, as it impairs the ability of oligodendrocytes to support neurons with metabolic energy substrates. This leads to motor neuron loss without oligodendroglial alterations and without changes in myelination [4]. Motor neurons are mainly affected due to their high energy needs [4].

More controversy exists on the ability of neuronal degeneration to induce oligodendrocyte degeneration. Many studies show that the survival of oligodendrocytes depends on neurons, but this is only the case during development and early postnatal life [134-137]. During adult life, differentiated oligodendrocytes are not dependent on axons for their survival [137-140]. In vivo experiments have shown that axon transections do not lead to secondary loss of adult mature oligodendrocytes, but only block the development of the immature oligodendrocytes [138]. This indicates that the dependency of oligodendrocytes on survival factors from the neurons diminishes with differentiation [138]. In contrast, widespread axonal degeneration leads to oligodendrocyte loss [141] and reactive changes in the NG2+ oligodendroglial precursor cells [142]. This suggests that once motor neuron degeneration is started, this can contribute to the progression of oligodendrocyte pathology and to the inhibition of the oligodendroglial differentiation process.
In this way, oligodendrocyte dysfunction and degeneration can be secondary to motor neuron degeneration in ALS. As a consequence, we consider motor neuron degeneration as one of the factors contributing to 'the third phase of damage' in our model of oligodendrocyte pathology (Figure 2). Although motor neuron degeneration is not actively contributing to the initiation of oligodendrocyte pathology, motor neurons make their surrounding oligodendrocytes more vulnerable than oligodendrocytes in other regions. This is due to their high energy requirements. Oligodendrocytes associated with high metabolic demanding motor neurons need higher levels of energy for their normal function than oligodendrocytes associated to other types of neurons [143]. In addition, they generate higher levels of damaging oxidative reactions during mitochondrial respiration due to the high metabolic demand of gray matter oligodendrocytes [40]. This may contribute to the selective degeneration of the oligodendrocytes associated with motor neurons, while the oligodendrocytes in other regions survive.

Based on all this information, it is likely that the initiation of oligodendrocyte pathology, namely the first phase of damage to the oligodendrocytes (Figure 2), is induced independent of motor neuron degeneration. However, once motor neurons start to degenerate they could be one of the factors contributing to the enhancement of this degenerative process of the oligodendroglial lineage cells (phase 3, Figure 2).

\section{Conclusion \& future perspective}

The potential role of oligodendrocytes in neurodegenerative diseases was underestimated for many years. Recent findings changed the scene of the pathogenesis of ALS and demonstrated the importance of oligodendrocytes for motor neurons. Insights from other diseases involving oligodendrocytes can help us to understand the full spectrum of damaging events targeting the oligodendrocytes and how these events contribute to neurodegeneration. The oligodendroglial pathology in ALS, including degeneration of oligodendrocytes and impaired maturation of new oligodendrocytes, and the involvement in neurodegeneration, shows some similarities with MS. Consequently, it is crucial to bring these two research fields together and to share knowledge. As reported previously in this review, several genes and pathways, such as Notch signaling, Wnt-signaling, Nogo-A 
and Id $2 /$ Id4, are known to be involved in differentiation, myelination and regeneration of the oligodendrocytes $[102,103]$. They are extensively studied in MS and can be considered as promising therapeutic targets. Up to now these genes and pathways have not been studied in the context of ALS oligodendroglial pathology. We believe that, in analogy to MS, the study of these pathways in ALS can be of major interest for the future. Restoring oligodendrocyte functioning and neutralizing the arrest of oligodendroglial differentiation and maturation can be interesting targets for therapeutic intervention in order to stop the vicious cycle of oligodendrocyte-neuron degeneration, for both ALS and MS.

\section{Financial \& competing interests disclosure}

The authors have received funding from the Fund for Scientific Research Flanders (FWO), Government Agency for Innovation by Science and Technology (IWT), University of Leuven, Interuniversity Attraction Poles program of the Belgian Federal Science Policy Office and the European Community's Health Seventh Framework Programme. A Nonneman receives a PhD fellowship from IWT. W Robberecht is supported through the E. von Behring Chair for Neuromuscular and Neurodegenerative Disorders. The authors have no other relevant affiliations or financial involvement with any organization or entity with a financial interest in or financial conflict with the subject matter or materials discussed in the manuscript apart from those disclosed.

No writing assistance was utilized in the production of this manuscript.

\section{References}

Papers of special note have been highlighted as:

- of interest $\bullet$ of considerable interest

1 Nave KA. Myelination and support of axonal integrity by glia. Nature 468(7321), 244-252 (2010).

2 Nave KA. Myelination and the trophic support of long axons. Nat. Rev. Neurosci. 11(4), 275-283 (2010).

3 Simons M, Lyons DA. Axonal selection and myelin sheath generation in the central nervous system. Curr. Opin. Cell. Biol. 25(4), 512-519 (2013).

4 Lee Y, Morrison BM, Li Y et al. Oligodendroglia metabolically support axons and contribute to neurodegeneration. Nature 487(7408), 443-448 (2012).

-• Demonstrates that oligodendroglia support neurons and axons by transporting lactate through the monocarboxylate transporter MCT1.

5 Morrison BM, Lee Y, Rothstein JD. Oligodendroglia: metabolic supporters of axons. Trends Cell. Biol. 23(12), 644-651 (2013).

6 Wijesekera LC, Leigh PN. Amyotrophic lateral sclerosis. Orphanet. J. Rare Dis. 4, 3 (2009).

7 Renton AE, Chio A, Traynor BJ. State of play in amyotrophic lateral sclerosis genetics. Nat. Neurosci. 17(1), 17-23 (2014).

8 Renton AE, Majounie E, Waite A et al. A hexanucleotide repeat expansion in C9ORF72 is the cause of chromosome 9p21-linked ALS-FTD. Neuron 72(2), 257-268 (2011)

9 Dejesus-Hernandez M, Mackenzie IR, Boeve BF et al. Expanded GGGGCC hexanucleotide repeat in noncoding region of C9ORF72 causes chromosome 9p-linked FTD and ALS. Neuron 72(2), 245-256 (2011).

10 Murray ME, Dejesus-Hernandez M, Rutherford NJ et al. Clinical and neuropathologic heterogeneity of c9FTD/ALS associated with hexanucleotide repeat expansion in C9ORF72. Acta Neuropathol. 122(6), 673-690 (2011).

11 Rosen DR. Mutations in Cu/Zn superoxide dismutase gene are associated with familial amyotrophic lateral sclerosis. Nature 364(6435), 362 (1993).

12 Sreedharan J, Blair IP, Tripathi VB et al. TDP-43 mutations in familial and sporadic amyotrophic lateral sclerosis. Science 319(5870), 1668-1672 (2008).

13 Kwiatkowski TJ Jr, Bosco DA, Leclerc AL et al. Mutations in the FUS/TLS gene on chromosome 16 cause familial amyotrophic lateral sclerosis. Science 323(5918), 1205-1208 (2009).

14 Vance C, Rogelj B, Hortobagyi T et al. Mutations in FUS, an RNA processing protein, cause familial amyotrophic lateral sclerosis type 6. Science 323(5918), 1208-1211 (2009).

15 Johnson JO, Mandrioli J, Benatar M et al. Exome sequencing reveals VCP mutations as a cause of familial ALS. Neuron 68(5), 857-864 (2010).

16 Gurney ME. Transgenic-mouse model of amyotrophic lateral sclerosis. N. Engl. J. Med. 331(25), 1721-1722 (1994).

17 Clement AM, Nguyen MD, Roberts EA et al. Wild-type nonneuronal cells extend survival of SOD1 mutant motor neurons in ALS mice. Science 302 (5642), 113-117 (2003).
18 Boillee S, Yamanaka K, Lobsiger CS et al. Onset and progression in inherited ALS determined by motor neurons and microglia. Science 312 (5778), 1389-1392 (2006).

19 Yamanaka K, Chun SJ, Boillee S et al. Astrocytes as determinants of disease progression in inherited amyotrophic lateral sclerosis. Nat. Neurosci. 11(3), 251-253 (2008).

20 Niebroj-Dobosz I, Rafalowska J, Fidzianska A, Gadamski R, Grieb P. Myelin composition of spinal cord in a model of amyotrophic lateral sclerosis (ALS) in SOD1G93A transgenic rats. Folia Neuropathol. 45(4), 236-241 (2007).

- Shows abnormalities in myelin and its composition.

21 Seilhean D, Cazeneuve C, Thuries V et al. Accumulation of TDP- 43 and alpha-actin in an amyotrophic lateral sclerosis patient with the K17I ANG mutation. Acta Neuropathol. 118(4), 561-573 (2009).

22 Mackenzie IR, Ansorge O, Strong M et al. Pathological heterogeneity in amyotrophic lateral sclerosis with FUS mutations: two distinct patterns correlating with disease severity and mutation. Acta Neuropathol. 122(1), 87-98 (2011).

23 Neumann M, Kwong LK, Truax AC et al. TDP-43-positive white matter pathology in frontotemporal lobar degeneration with ubiquitin-positive inclusions. J. Neuropathol. Exp. Neurol. 66(3), 177-183 (2007).

24 Nave KA, Trapp BD. Axon-glial signaling and the glial support of axon function. Annu. Rev. Neurosci. 31, 535-561 (2008).

25 White R, Kramer-Albers EM. Axon-glia interaction and membrane traffic in myelin 
formation. Front. Cell. Neurosci. 7, 284 (2014).

26 Poliak S, Peles E. The local differentiation of myelinated axons at nodes of Ranvier. Nat. Rev. Neurosci. 4(12), 968-980 (2003).

27 Pierre K, Pellerin L. Monocarboxylate transporters in the central nervous system: distribution, regulation and function. J. Neurochem. 94(1), 1-14 (2005).

28 Rinholm JE, Hamilton NB, Kessaris N, Richardson WD, Bergersen LH, Attwell D. Regulation of oligodendrocyte development and myelination by glucose and lactate. J. Neurosci. 31(2), 538-548 (2011).

29 Chiry O, Pellerin L, Monnet-Tschudi F et al. Expression of the monocarboxylate transporter MCT1 in the adult human brain cortex. Brain Res. 1070 (1), 65-70 (2006).

30 Pierre K, Pellerin L, Debernardi R, Riederer BM, Magistretti PJ. Cell-specific localization of monocarboxylate transporters, MCT1 and MCT2, in the adult mouse brain revealed by double immunohistochemical labeling and confocal microscopy. Neuroscience 100 (3), 617-627 (2000).

31 Miller RH. Oligodendrocyte origins. Trends Neurosci. 19(3), 92-96 (1996).

32 Richardson WD, Pringle NP, Yu WP, Hall AC. Origins of spinal cord oligodendrocytes: possible developmental and evolutionary relationships with motor neurons. Dev. Neurosci. 19(1), 58-68 (1997).

33 Rogister B, Ben-Hur T, Dubois-Dalcq M. From neural stem cells to myelinating oligodendrocytes. Mol. Cell. Neurosci. 14(4-5), 287-300 (1999).

34 De Castro F, Bribian A. The molecular orchestra of the migration of oligodendrocyte precursors during development. Brain Res. Brain Res. Rev. 49(2), 227-241 (2005).

35 Nishiyama A, Komitova M, Suzuki R, Zhu X. Polydendrocytes (NG2 cells): multifunctional cells with lineage plasticity. Nat. Rev. Neurosci. 10(1), 9-22 (2009).

36 Trotter J, Karram K, Nishiyama A. NG2 cells: properties, progeny and origin. Brain Res. Rev 63(1-2), 72-82 (2010).

37 Levine JM, Reynolds R, Fawcett JW. The oligodendrocyte precursor cell in health and disease. Trends Neurosci. 24(1), 39-47 (2001).

38 Potter GB, Rowitch DH, Petryniak MA. Myelin restoration: progress and prospects for human cell replacement therapies. Arch. Immunol. Ther. Ex. 59(3), 179-193 (2011).

39 Almeida RG, Czopka T, Ffrench-Constant C, Lyons DA. Individual axons regulate the myelinating potential of single oligodendrocytes in vivo. Development 138 (20), 4443-4450 (2011).

40 Bartzokis G. Age-related myelin breakdown: a developmental model of cognitive decline and Alzheimer's disease. Neurobiol. Aging 25(1), 5-18; author reply 49-62 (2004).

41 Young KM, Psachoulia K, Tripathi RB et al. Oligodendrocyte dynamics in the healthy adult CNS. Evidence for myelin remodeling. Neuron 77(5), 873-885 (2013).

42 Keirstead HS, Blakemore WF. Identification of post-mitotic oligodendrocytes incapable of remyelination within the demyelinated adult spinal cord. J. Neuropathol. Exp. Neurol. 56(11), 1191-1201 (1997).

43 Kang SH, Fukaya M, Yang JK, Rothstein JD, Bergles DE. NG2+ CNS glial progenitors remain committed to the oligodendrocyte lineage in postnatal life and following neurodegeneration. Neuron 68(4), 668-681 (2010).

-• Provides evidence that NG2 + glial cells exhibit enhanced proliferation and differentiation into oligodendrocytes in the spinal cord of amyotrophic lateral sclerosis (ALS) mice.

44 Butt AM, Kiff J, Hubbard P, Berry M. Synantocytes: new functions for novel NG2 expressing glia. J. Neurocytol. 31(6-7), 551-565 (2002).

45 Bergles DE, Jabs R, Steinhauser C. Neuron-glia synapses in the brain. Brain Res. Rev. 63(1-2), 130-137 (2010).

46 Hampton DW, Rhodes KE, Zhao C, Franklin RJ, Fawcett JW. The responses of oligodendrocyte precursor cells, astrocytes and microglia to a cortical stab injury, in the brain. Neuroscience 127(4), 813-820 (2004).

47 Mcdonald JW, Belegu V. Demyelination and remyelination after spinal cord injury. J. Neurotrauma 23(3-4), 345-359 (2006).

48 Keirstead HS, Levine JM, Blakemore WF. Response of the oligodendrocyte progenitor cell population (defined by NG2 labelling) to demyelination of the adult spinal cord. Glia 22(2), 161-170 (1998).

49 Reynolds R, Cenci Di Bello I, Dawson M, Levine J. The response of adult oligodendrocyte progenitors to demyelination in EAE. Prog. Brain Res. 132, 165-174 (2001).

50 Reynolds R, Dawson M, Papadopoulos D et al. The response of NG2-expressing oligodendrocyte progenitors to demyelination in MOG-EAE and MS. J. Neurocytol. 31(6-7), 523-536 (2002)
51 Richardson WD, Young KM, Tripathi RB, Mckenzie I. NG2-glia as multipotent neural stem cells: fact or fantasy? Neuron 70(4), 661-673 (2011).

52 Guo F, Ma J, Mccauley E, Bannerman P, Pleasure D. Early postnatal proteolipid promoter-expressing progenitors produce multilineage cells in vivo. J. Neurosci. 29(22), 7256-7270 (2009).

53 Rivers LE, Young KM, Rizzi M et al. PDGFRA/NG2 glia generate myelinating oligodendrocytes and piriform projection neurons in adult mice. Nat. Neurosci. 11(12), 1392-1401 (2008).

54 Zhu X, Bergles DE, Nishiyama A. NG2 cells generate both oligodendrocytes and gray matter astrocytes. Development 135(1), 145-157 (2008).

55 Zhu X, Hill RA, Nishiyama A. NG2 cells generate oligodendrocytes and gray matter astrocytes in the spinal cord. Neuron Glia Biol. 4(1), 19-26 (2008).

56 Zawadzka M, Rivers LE, Fancy SP et al. CNS-resident glial progenitor/stem cells produce Schwann cells as well as oligodendrocytes during repair of CNS demyelination. Cell Stem Cell 6(6), 578-590 (2010).

57 Belachew S, Chittajallu R, Aguirre AA et al. Postnatal NG2 proteoglycan-expressing progenitor cells are intrinsically multipotent and generate functional neurons. J. Cell. Biol. 161(1), 169-186 (2003).

58 Cassiani-Ingoni R, Coksaygan $\mathrm{T}$, Xue $\mathrm{H}$ et al. Cytoplasmic translocation of Olig2 in adult glial progenitors marks the generation of reactive astrocytes following autoimmune inflammation. Exp. Neurol. 201(2), 349-358 (2006).

59 Sellers DL, Maris DO, Horner PJ. Postinjury niches induce temporal shifts in progenitor fates to direct lesion repair after spinal cord injury. J. Neurosci. 29(20), 6722-6733 (2009).

60 Zhu X, Hill RA, Dietrich D, Komitova M, Suzuki R, Nishiyama A. Age-dependent fate and lineage restriction of single NG2 cells. Development 138(4), 745-753 (2011).

61 Arai T, Hasegawa M, Akiyama $\mathrm{H}$ et al. TDP-43 is a component of ubiquitin-positive tau-negative inclusions in frontotemporal lobar degeneration and amyotrophic lateral sclerosis. Biochem. Biophys. Res. Commun. 351(3), 602-611 (2006).

62 Mackenzie IR, Bigio EH, Ince PG et al. Pathological TDP-43 distinguishes sporadic amyotrophic lateral sclerosis from amyotrophic lateral sclerosis with SOD1 
mutations. Ann. Neurol. 61(5), 427-434 (2007).

63 Tan CF, Eguchi H, Tagawa A et al. TDP-43 immunoreactivity in neuronal inclusions in familial amyotrophic lateral sclerosis with or without SOD1 gene mutation. Acta Neuropathol. 113(5), 535-542 (2007). Zhang H, Tan CF, Mori F et al. TDP-43immunoreactive neuronal and glial inclusions in the neostriatum in amyotrophic lateral sclerosis with and without dementia. Acta Neuropathol. 115(1), 115-122 (2008).

65 Philips T, Bento-Abreu A, Nonneman A et al. Oligodendrocyte dysfunction in the pathogenesis of amyotrophic lateral sclerosis. Brain 136(Pt 2), 471-482 (2013).

-. Reports the involvement of oligodendrocytes in the pathogenesis of ALS.

66 Kang SH, Li Y, Fukaya M et al. Degeneration and impaired regeneration of gray matter oligodendrocytes in amyotrophic lateral sclerosis. Nat. Neurosci. 16(5), 571-579 (2013).

-. Extensive study of the oligodendrocyte pathology in ALS and its effect on disease onset and survival.

67 Stieber A, Gonatas JO, Gonatas NK. Aggregates of mutant protein appear progressively in dendrites, in periaxonal processes of oligodendrocytes, and in neuronal and astrocytic perikarya of mice expressing the SOD1(G93A) mutation of familial amyotrophic lateral sclerosis. $J$. Neurol. Sci. 177(2), 114-123 (2000).

68 Taylor RC, Cullen SP, Martin SJ. Apoptosis: controlled demolition at the cellular level. Nat Rev Mol. Cell Biol. 9(3), 231-241 (2008).

69 Davalos D, Grutzendler J, Yang G et al. ATP mediates rapid microglial response to local brain injury in vivo. Nat. Neurosci. 8(6), 752-758 (2005).

70 Magnus T, Carmen J, Deleon J et al. Adult glial precursor proliferation in mutant SOD1G93A mice. Glia 56(2), 200-208 (2008).

71 Polito A, Reynolds R. NG2-expressing cells as oligodendrocyte progenitors in the normal and demyelinated adult central nervous system. J. Anat. 207(6), 707-716 (2005).

72 Andersson S, Gustafsson N, Warner M, Gustafsson JA. Inactivation of liver X receptor beta leads to adult-onset motor neuron degeneration in male mice. Proc. Natl Acad. Sci. USA 102(10), 3857-3862 (2005).

73 Boggs JM. Myelin basic protein: a multifunctional protein. Cell. Mol. Life Sci. 63(17), 1945-1961 (2006).
74 Braak H, Del Tredici K. Poor and protracted myelination as a contributory factor to neurodegenerative disorders. Neurobiol. Aging 25(1), 19-23 (2004).

75 Sanchez-Abarca LI, Tabernero A, Medina JM. Oligodendrocytes use lactate as a source of energy and as a precursor of lipids. Glia 36(3), 321-329 (2001).

76 Higuchi M, Zhang B, Forman MS, Yoshiyama Y, Trojanowski JQ, Lee VM. Axonal degeneration induced by targeted expression of mutant human tau in oligodendrocytes of transgenic mice that model glial tauopathies. J. Neurosci. 25(41), 9434-9443 (2005).

77 Yazawa I, Giasson BI, Sasaki R et al. Mouse model of multiple system atrophy alphasynuclein expression in oligodendrocytes causes glial and neuronal degeneration. Neuron 45(6), 847-859 (2005).

78 Merrill JE, Ignarro LJ, Sherman MP, Melinek J, Lane TE. Microglial cell cytotoxicity of oligodendrocytes is mediated through nitric oxide. J. Immunol. 151(4), 2132-2141 (1993).

79 Mitrovic B, Ignarro LJ, Vinters HV et al. Nitric oxide induces necrotic but not apoptotic cell death in oligodendrocytes. Neuroscience 65(2), 531-539 (1995).

80 Yeo YA, Martinez Gomez JM, Croxford JL, Gasser S, Ling EA, Schwarz H. CD137 ligand activated microglia induces oligodendrocyte apoptosis via reactive oxygen species. J. Neuroinflammation 9, 173 (2012).

81 Li J, Baud O, Vartanian T, Volpe JJ, Rosenberg PA. Peroxynitrite generated by inducible nitric oxide synthase and NADPH oxidase mediates microglial toxicity to oligodendrocytes. Proc. Natl Acad. Sci. USA 102(28), 9936-9941 (2005).

82 Pang Y, Campbell L, Zheng B, Fan L, Cai Z, Rhodes P. Lipopolysaccharide-activated microglia induce death of oligodendrocyte progenitor cells and impede their development. Neuroscience 166(2), 464-475 (2010).

83 Benveniste EN. Role of macrophages/ microglia in multiple sclerosis and experimental allergic encephalomyelitis. J. Mol. Med. (Berl) 75(3), 165-173 (1997).

84 Zhang SC, Goetz BD, Duncan ID. Suppression of activated microglia promotes survival and function of transplanted oligodendroglial progenitors. Glia 41(2), 191-198 (2003).

85 Baud O, Li J, Zhang Y, Neve RL, Volpe JJ, Rosenberg PA. Nitric oxide-induced cell death in developing oligodendrocytes is associated with mitochondrial dysfunction and apoptosis-inducing factor translocation. Eur. J. Neurosci. 20(7), 1713-1726 (2004).

86 Nakajima K, Kohsaka S. Microglia: neuroprotective and neurotrophic cells in the central nervous system. Curr Drug Targets Cardiovasc Haematol. Disord. 4(1), 65-84 (2004).

87 Palacios N, Sanchez-Franco F, Fernandez M, Sanchez I, Cacicedo L. Intracellular events mediating insulin-like growth factor I-induced oligodendrocyte development: modulation by cyclic AMP. J. Neurochem. 95(4), 1091-1107 (2005).

88 Talbott JF, Cao Q, Bertram J et al. CNTF promotes the survival and differentiation of adult spinal cord-derived oligodendrocyte precursor cells in vitro but fails to promote remyelination in vivo. Exp. Neurol. 204(1), 485-489 (2007).

89 Moore CS, Abdullah SL, Brown A, Arulpragasam A, Crocker SJ. How factors secreted from astrocytes impact myelin repair. J. Neurosci. Res. 89(1), 13-21 (2011).

90 Haidet-Phillips AM, Hester ME, Miranda CJ et al. Astrocytes from familial and sporadic ALS patients are toxic to motor neurons. Nat. Biotechnol. 29(9), 824-828 (2011).

91 Diaz-Amarilla P, Olivera-Bravo S, Trias E et al. Phenotypically aberrant astrocytes that promote motoneuron damage in a model of inherited amyotrophic lateral sclerosis. Proc. Natl Acad. Sci. USA 108(44), 18126-18131 (2011).

92 Sasaki S, Warita H, Abe K, Iwata M. Inducible nitric oxide synthase (iNOS) and nitrotyrosine immunoreactivity in the spinal cords of transgenic mice with a G93A mutant SOD1 gene. J. Neuropathol. Exp. Neurol. 60(9), 839-846 (2001).

93 French HM, Reid M, Mamontov P, Simmons RA, Grinspan JB. Oxidative stress disrupts oligodendrocyte maturation. J. Neurosci. Res. 87(14), 3076-3087 (2009).

94 Chang Y, Kong Q, Shan X et al. Messenger RNA oxidation occurs early in disease pathogenesis and promotes motor neuron degeneration in ALS. PLoS ONE 3(8), e2849 (2008).

-. Demonstrates that oxidative damage contributes to oligodendrocyte pathology in ALS.

95 Kowaltowski AJ, Vercesi AE. Mitochondrial damage induced by conditions of oxidative stress. Free Radic. Biol. Med. 26(3-4), 463-471 (1999).

96 Van Den Bosch L, Van Damme P, Bogaert E, Robberecht W. The role of excitotoxicity in the pathogenesis of amyotrophic lateral 
sclerosis. Biochim. Biophys. Acta 1762(11-12), 1068-1082 (2006).

97 Bogaert E, d'Ydewalle C, Van Den Bosch L. Amyotrophic lateral sclerosis and excitotoxicity: from pathological mechanism to therapeutic target. CNS Neurol. Disord. Drug Targets 9(3), 297-304 (2010).

98 Matute C, Sanchez-Gomez MV, MartinezMillan L, Miledi R. Glutamate receptormediated toxicity in optic nerve oligodendrocytes. Proc. Natl Acad. Sci. USA 94(16), 8830-8835 (1997).

99 Mcdonald JW, Levine JM, Qu Y. Multiple classes of the oligodendrocyte lineage are highly vulnerable to excitotoxicity. Neuroreport 9(12), 2757-2762 (1998).

100 Salter MG, Fern R. NMDA receptors are expressed in developing oligodendrocyte processes and mediate injury. Nature 438 (7071), 1167-1171 (2005).

101 Micu I, Jiang Q, Coderre E et al. NMDA receptors mediate calcium accumulation in myelin during chemical ischaemia. Nature 439(7079), 988-992 (2006).

102 Kremer D, Aktas O, Hartung HP, Kury P. The complex world of oligodendroglial differentiation inhibitors. Ann. Neurol. 69(4), 602-618 (2011).

103 Kotter MR, Stadelmann C, Hartung HP. Enhancing remyelination in disease--can we wrap it up? Brain 134(Pt 7), 1882-1900 (2011).

104 Wang S, Sdrulla AD, Disibio G et al. Notch receptor activation inhibits oligodend rocyte differentiation. Neuron 21(1), 63-75 (1998).

105 John GR, Shankar SL, Shafit-Zagardo B et al. Multiple sclerosis: re-expression of a developmental pathway that restricts oligodendrocyte maturation. Nat. Med. 8(10), 1115-1121 (2002).

106 Jurynczyk M, Selmaj K. Notch: a new player in MS mechanisms. J. Neuroimmunol. 218(1-2), 3-11 (2010).

107 Li H, Richardson WD. Genetics meets epigenetics: HDACs and Wnt signaling in myelin development and regeneration. Nat. Neurosci. 12(7), 815-817 (2009).

108 Feigenson K, Reid M, See J, Crenshaw EB, 3rd, Grinspan JB. Wnt signaling is sufficient to perturb oligodendrocyte maturation. Mol. Cell. Neurosci. 42(3), 255-265 (2009).

109 Ye F, Chen Y, Hoang T et al. HDAC1 and HDAC2 regulate oligodendrocyte differentiation by disrupting the beta-cateninTCF interaction. Nat. Neurosci. 12(7), 829-838 (2009).
110 Fancy SP, Baranzini SE, Zhao C et al. Dysregulation of the Wnt pathway inhibits timely myelination and remyelination in the mammalian CNS. Genes Dev. 23(13), 1571-1585 (2009).

111 Chong SY, Rosenberg SS, Fancy SP et al. Neurite outgrowth inhibitor Nogo-A establishes spatial segregation and extent of oligodendrocyte myelination. Proc. Natl Acad. Sci. USA 109(4), 1299-1304 (2012).

112 Schmandke A, Schwab ME. Nogo-A. Multiple Roles in CNS Development, Maintenance, and Disease. Neuroscientist (2014) (Epub ahead of print).

113 Satoh J, Onoue H, Arima K, Yamamura T. Nogo-A and nogo receptor expression in demyelinating lesions of multiple sclerosis. J. Neuropathol. Exp. Neurol. 64(2), 129-138 (2005).

114 Theotokis P, Lourbopoulos A, Touloumi O et al. Time course and spatial profile of Nogo-A expression in experimental autoimmune encephalomyelitis in $\mathrm{C} 57 \mathrm{BL} / 6$ mice. J. Neuropathol. Exp. Neurol. 71(10), 907-920 (2012).

115 Fontoura P, Ho PP, Devoss J et al. Immunity to the extracellular domain of Nogo-A modulates experimental autoimmune encephalomyelitis. J. Immunol. 173(11), 6981-6992 (2004).

116 Karnezis T, Mandemakers W, Mcqualter JL et al. The neurite outgrowth inhibitor Nogo A is involved in autoimmune-mediated demyelination. Nat. Neurosci. 7(7), 736-744 (2004).

117 Chen XS, Zhang YH, Cai QY, Yao ZX. ID2: a negative transcription factor regulating oligodendroglia differentiation. J. Neurosci. Res. 90(5), 925-932 (2012).

118 Kondo T, Raff M. The Id 4 HLH protein and the timing of oligodendrocyte differentiation. EMBO J. 19(9), 1998-2007 (2000).

119 Marin-Husstege M, He Y, Li J, Kondo T, Sablitzky F, Casaccia-Bonnefil P. Multiple roles of Id 4 in developmental myelination: predicted outcomes and unexpected findings. Glia 54(4), 285-296 (2006).

120 Perron H, Dougier-Reynaud HL, Lomparski $\mathrm{C}$ et al. Human endogenous retrovirus protein activates innate immunity and promotes experimental allergic encephalomyelitis in mice. PLoS ONE 8(12), e80128 (2013).

121 Kremer D, Schichel T, Forster M et al. Human endogenous retrovirus type W envelope protein inhibits oligodendroglial precursor cell differentiation. Ann. Neurol. 74(5), 721-732 (2013).
122 Antony JM, Van Marle G, Opii W et al. Human endogenous retrovirus glycoproteinmediated induction of redox reactants causes oligodendrocyte death and demyelination. Nat. Neurosci. 7(10), 1088-1095 (2004).

123 Douville R, Liu J, Rothstein J, Nath A. Identification of active loci of a human endogenous retrovirus in neurons of patients with amyotrophic lateral sclerosis. Ann. Neurol. 69(1), 141-151 (2011).

124 Appel SH, Zhao W, Beers DR, Henkel JS. The microglial-motoneuron dialogue in ALS. Acta Myol. 30 (1), 4-8 (2011).

125 Ferguson B, Matyszak MK, Esiri MM, Perry $\mathrm{VH}$. Axonal damage in acute multiple sclerosis lesions. Brain 120 (Pt 3), 393-399 (1997).

126 Trapp BD, Peterson J, Ransohoff RM, Rudick $\mathrm{R}$, Mork S, Bo L. Axonal transection in the lesions of multiple sclerosis. N. Engl. J. Med. 338(5), 278-285 (1998).

127 Griffiths I, Klugmann M, Anderson T et al. Axonal swellings and degeneration in mice lacking the major proteolipid of myelin. Science 280(5369), 1610-1613 (1998).

128 Garbern JY, Yool DA, Moore GJ et al. Patients lacking the major CNS myelin protein, proteolipid protein 1 , develop length-dependent axonal degeneration in the absence of demyelination and inflammation. Brain 125(Pt 3), 551-561 (2002).

129 Pohl HB, Porcheri C, Mueggler T et al. Genetically induced adult oligodendrocyte cell death is associated with poor myelin clearance, reduced remyelination, and axonal damage. J. Neurosci. 31(3), 1069-1080 (2011).

- Shows how oligodendrocyte degeneration can be responsible for axonal damage.

130 Locatelli G, Wortge S, Buch T et al. Primary oligodendrocyte death does not elicit anti-CNS immunity. Nat. Neurosci. 15(4), 543-550 (2012).

131 Oluich LJ, Stratton JA, Xing YL et al. Targeted ablation of oligodendrocytes induces axonal pathology independent of overt demyelination. J. Neurosci. 32(24), 8317-8330 (2012).

132 Ghosh A, Manrique-Hoyos N, Voigt A et al. Targeted ablation of oligodendrocytes triggers axonal damage. PLoS ONE 6(7), e22735 (2011).

133 Smith CM, Cooksey E, Duncan ID. Myelin loss does not lead to axonal degeneration in a long-lived model of chronic demyelination. J. Neurosci. 33(6), 2718-2727 (2013).

134 Barres BA, Jacobson MD, Schmid R, Sendtner M, Raff MC. Does oligodendrocyte survival depend on axons? Curr. Biol. 3(8), 489-497 (1993). 
135 Barres BA, Raff MC. Axonal control of oligodendrocyte development. J. Cell. Biol. 147(6), 1123-1128 (1999).

136 Fernandez PA, Tang DG, Cheng L, Prochiantz A, Mudge AW, Raff MC. Evidence that axon-derived neuregulin promotes oligodendrocyte survival in the developing rat optic nerve. Neuron 28(1), 81-90 (2000).

137 Fulcrand J, Privat A. Neuroglial reactions secondary to Wallerian degeneration in the optic nerve of the postnatal rat: ultrastructural and quantitative study. J. Comp. Neurol. 176(2), 189-222 (1977).
138 Greenwood K, Butt AM. Evidence that perinatal and adult NG2-glia are not conventional oligodendrocyte progenitors and do not depend on axons for their survival. Mol. Cell. Neurosci. 23(4), 544-558 (2003).

139 Ludwin SK. Oligodendrocyte survival in Wallerian degeneration. Acta Neuropathol. 80(2), 184-191 (1990).

140 Vaughn JE, Pease DC. Electron microscopic studies of wallerian degeneration in rat optic nerves. II. Astrocytes, oligodendrocytes and adventitial cells. J. Comp. Neurol. 140(2), 207-226 (1970).
141 Jamin N, Junier MP, Grannec G, Cadusseau J. Two temporal stages of oligodendroglial response to excitotoxic lesion in the gray matter of the adult rat brain. Exp. Neurol. 172(1), 17-28 (2001).

142 Wu YJ, Tang YF, Xiao ZC, Bao ZM, He BP. NG2 cells response to axonal alteration in the spinal cord white matter in mice with genetic disruption of neurofilament light subunit expression. Mol. Neurodegener. 3, 18 (2008).

143 Barros LF. Metabolic signaling by lactate in the brain. Trends Neurosci. 36(7), 396-404 (2013). 